\title{
A PERCEPÇÃO DOS DOCENTES UNIVERSITÁRIOS À RESPEITO DE SUA CAPACITAÇÃO PARA O ENSINO EM ENFERMAGEM.
}

\author{
THE TEACHER'S UNDERSTANDING ABOUT THEIR ABILITY \\ IN NURSING TEACHING
}

\author{
Heloisa Helena Ciqueto Peres* \\ Maria Madalena Januário Leite*** \\ Paulina Kurcgant**
}

PERES, H.H.C. A percepçao dos docentes universitários à respeito de sua capacitação para o ensino da enfermagem. Rev.Esc.Enf.USP, v.32, n.1, p.52-8, abr. 1998 .

\begin{abstract}
RESUMO
Como docentes da disciplina Administração aplicada à Enfermagem, há muito vem nos inquietando as múltiplas variáveis do processo educativo que afetam tanto o professor quanto o aluno, como interesses, atitudes, formas de pensar e agir, valores, expectativas, experiências anteriores, entre outros.Essas inquietações levam-nos a repensar a forma de vivenciar a prática educacional, refletindo sobre a capacitação docente. Para tanto propomo-nos a desvelar, neste estudo, as percepcóes dos docentes universitários no referente à própria capacitação para o ensino de enfermagem, objetivando conhecer uma parcela dessa realidade no meio acadêmico. Para tanto foi adotada uma metodologia qualitativa que permitesse a análise compreensiva dos discursos de docentes que atuam em uma instituição pública de ensino superior, na cidade de São Paulo. De acordo com a metodologia proposta foram resgatadas quatro unidades de significado que permitiram a formulação dos seguintes temas emergentes: Percepção dos docentes quanto à capacitação técnica; Percepção dos docentes quanto à capacitação teórico-cientifica; Percepcão dos docentes quanto à capacitação pedagógica e Considerações dos docentes quanto à identificação com o ensino. $O$ estudo possibilitou o desvelamento de relevantes facetas, a respeito da capacitação do docente, resgatandoa como resultante de $u \mathrm{~m}$ processo complexo e contínuo de preparo técnico, teórico e pedagógico, influenciado por fatores, psicológicos, sociais, éticos, econômicos, politicos e históricos. Pudemos resgatar ainda que as reflexões dos docentes a respeito da realidade de ensino, na sua totalidade, favoreceram a tomada de consciência e interferiram, positivamente, na sua formação crítica e foi resgatada a necessidade das escolas criarem Centros de Formação $e$ Atualização de professores, estabelecendo políticas de ação educacional renovadoras e de recursos humanos compatíveis com as transformações sociais.
\end{abstract}

UNITERMOS : Ensino superior. Educação em enfermagem. Capacitação docente.

\section{ABSTRACT}

Teaching Administration Nursing Service we've been worried about several variables of the instructive process that affect the teachers and the students, as advantage, attitudes, thinking and acting manner, values, expectations, previous experiences, among some.These uneasiness take us to check the educational practice experience, considering the teaching's ability. In this study, we intend to reveal the teacher's understanding about the ability to teach nursing throw the education's reality recognition. So, we adopted a quality methodology that allow us a comprehensive analysis of the teaching's speech at a Public University in São Paulo city. According to the methodology it was possible to get back four meaning unities that allowed us to prescribe the emerging subjects; teaching's understanding about technical ability, teaching's understanding about scientific-theretical ability, teaching's understanding about pedagogical ability and the teaching identity. This study permitted us to reveal some points considered outstanding about the teacher's ability, getling it back as the result in a complex and continuous process of technical, theoretical and pedagogical training, contained in a several factors, psycological, social, ethical, economical, political and historical. We still understanding that the teacher's reflections about the teaching reality, in its totality, favouring the awareness and interfering positivly in their criticism formation. Finally there is a necessity to set up schools formation and up-dating centers and establish human political resources compatible with a renewed political of na educational action.

UNITERMS: University education. Nursing teaching. Teaching's ability.

\footnotetext{
* Enfermeira. Professora Assistente do Departamento de Orientação Profissional da EEUSP.

* Enfermeira. Professora Titular do Departamento de Orientaçao Profissional da EEUSP.

** Enfermeira. Professora Doutora do Departamento de Orientação Profissional da EEUSP.
} 


\section{INTRODUÇÃO}

A educação é uma questão importante considerando-se, principalmente, as mudanças que têm ocorrido no mundo e que se refletem, claramente, nas relações humanas no âmbito econômico, político, social e cultural. Este dinamismo transformador interfere profundamente no viver dos indivíduos e, conseqüentemente, nas questões educacionais que não podem estar afastadas deste contexto. Assim, o momento é de reflexão sobre as práticas educacionais, indagando-se como, porque e a quem educar, em toda a amplitude e essência.

Neste panorama de rápidas transformações da sociedade e do conhecimento, a educação tem se modificado e vem sendo concebida segundo diferentes vertentes que privilegiam tanto a dimensão humana quanto a técnica, a emocional, a sócio-política e a cultural, levando-nos a recolocar e a repensar a problemática da educação e da capacitação docente.

Considerando as várias abordagens educacionais MIZUKAMI ${ }^{7}$ destaca que na abordagem humanista o núcleo do processo ensino. aprendizagem é a relação interpessoal, que contempla a dimensão humana; na abordagem comportamentalista, há a dimensão técnica onde são privilegiados os aspectos objetivos, mensuráveis e controláveis; na abordagem tradicional o ensino está centrado no professor, e o aluno é considerado um "depositário" do saber, que precisa ser atualizado; na abordagem cognitivista o núcleo do processo de desenvolvimento visa a perspectiva interacionista, onde o conhecimento é o produto da interação do homem com o objeto, não enfatizando nenhum pólo de relação, como ocorre nas abordagens anteriores. $\mathrm{Na}$ abordagem sócio-cultural a ênfase se dá no sujeito como elaborador e criador do conhecimento, estando o homem inserido em um contexto histórico.

Faz-se necessário considerar que essas abordagens consubstanciam o comportamento dos professores até os dias de hoje estando, a maior tendência, no segmento de uma das correntes, dependendo dos objetivos institucionais, das propostas do educador e do processo político-social vigente. ${ }^{12}$

Em nossa experiência docente, na disciplina Administração aplicada à Enfermagem, há muito nos inquietam as múltiplas variáveis do processo educativo que afetam tanto o professor quanto o aluno; os interesses, as atitudes, as formas de pensar e agir, os valores, as expectativas, as experiências anteriores, o ambiente social, entre outros.

Essas inquietações nos levam a repensar a forma de vivenciar a prática educacional, a refletir sobre a capacitação do professor, considerando o docente como elemento mediador do processo ensinoaprendizagem.

Cabe ressaltar ainda que acreditamos no ensino de administração aplicada à enfermagem, voltado para a capacitação profissional pautada na reflexão sobre a natureza do processo de transformação social e de saúde. Considera-se, em especial, o papel que o profissional de enfermagem deve desempenhar, a competência técnico-científica e o compromisso na intervenção crítica da realidade, tendo por base a assistência prestada ao homem inserido em seu contexto histórico e em uma determinada classe social. ${ }^{4}$

Para tanto, acreditamos que a educação concretiza-se pelo diálogo e objetiva mudanças a partir da reflexão sobre a realidade. Nesta abordagem, o aluno é ativo, observador e indagador de suas opiniões e percepções.

Assim, a educação é concebida como um instrumento fundamental e essencial para a formação da consciência crítica e da capacitação específica dos indivíduos de uma dada sociedade.

Diante dessas considerações fica explícito a importância do professor como um dos elementos que se insere, intrinsecamente, no cerne do processo educacional e para tanto deve ter um preparo adequado, isto é, uma competência profissional.

Dessa forma para o reconhecimento de uma realidade de ensinoo presente estudo objetiva o conhecimento das percepções des docentes da disciplina Administração aplicada à Enfermagem, no que se refere à sua própria capacitação.

\section{METODOLOGIA}

O presente estudo tem por base os discursos obtidos em entrevistas com três docentes, da disciplina de administração aplicada à enfermagem, de uma instituição pública de ensino superior, da cidade de São Paulo.

Cabe ressaltar que se optou por delimitar a população do estudo aos docentes, da área de administração aplicada à enfermagem, por estarmos compartilhando desse cotidiano, ou seja, por sermos docentes da referida área de ensino.

Como critério para a definição da população, estabeleceu-se o docente que estivesse no início da carreira (cursando Pós-Graduação - Mestrado), outro que estivesse em fase mais adiantada da carreira (concluído Pó-Graduação - Mestre) e a chefe da disciplina (cursando Pós-Graduação - Doutorado). Cabe ressaltar que não havia docente com título de Doutor.

Para a coleta de dados foi adotada a técnica da entrevista semi-estruturada, utilizando-se, para 
a captação dos dados, o gravador e para a orientação das entrevistas foi utilizado um roteiro onde foram listados os topicos a serem explorados. (anexo I).

Para análise dos dados seguiu-se as fases propostas por BARDIN² : a pré-análise, a descrição analítica e a interpretação inferencial. Na préanálise o material é organizado; na descrição analitica o material é submetido a estudo aprofundado, sendo que, nessa etapa, utilizam-se procedimentos como codificação, classificação e categorização que buscam sínteses coincidentes e divergentes de idéias. $\mathrm{Na}$ fase de interpretação inferencial, a reflexão e a intuição possibilitam o estabelecimento de relações, desvelando o conteúdo latente dos discursos.

Adotando-se as orientações desse autor, na fase de organização dos dados, fez-se a transcrição integral das entrevistas, com o objetivo de se resgatar a percepção de todo o conteúdo temático gerado. Posteriormente iniciou-se a interpretação analítica dos discursos, na tentativa de serem identificadas similaridades para possível codificação e categorização.

Foram agrupadas falas referentes a um mesmo assunto intitulando cada conjunto com palavras chaves decorrentes dos próprios "discursos", sendo realizado a revisão das categorias, temas e conteúdos emergentes.

Assim foram identificadas quatro unidades de significado que permitiram a formulação dos seguintes temas: "Percepşão dos docentes quanto à capacitacão técnica específica"; "Percepção dos docentes quanto à capacitação teórico cientifica"; "Percepção dos docentes quanto à capacitação pedagógica"; "Considerações dos docentes quanto à identificação para o ensino".

Posteriormente, esses temas foram interpretados através de um processo reflexivo o que possibilitou o estabelecimento de relações com 0 referencial teórico existente sobre o assunto.

\section{APRESENTAÇÃO E DISCUSSÃO DOS DADOS}

\subsection{Percepção dos docentes quanto à capacitação técnica}

As falas das entrevistadas relativas a esse tema revelam a importância do preparo dos docentes na área técnica especifica de enfermagem relacionada aos procedimentos, técnicas, enfim aos aspectos práticos da profissão.

Fica evidente ainda que um dos fatores dificultadores da capacitação docente, nesta área, está centrado na própria estrutura organizacional da instituição de ensino, que distancia a escola da prática.

E. 1. “... hoje a minha maior preocupação é em termos da prática." (...) enquanto aluna, eu via que os professores que tinham tido uma vivência prática, eram muito melhores que aqueles que tinham ido direto para a docência. Então acho que esse é um ponto fundamental (...) a relação com a prática fica muito difícil pelo próprio contrato de trabalho..."

E.2. “... a própria capacitação na prática de enfermagem, deveria andar em conjunto com a teoria..."

MENEZES $^{6}$ considera que é de suma importância a competência prática do docente em sua especialidade, pois sem essa capacidade de intervenção prática, a teoria torna-se vazia, pautada em formulas que não conseguem ser captadas pelos alunos, ou seja, apenas a teoria em si, não basta para educar.

SILVA et al ${ }^{12}$ consideram que "enquanto os grandes debates permanecerem dentro das escolas, isolados dos problemas reais, tornando a teoria cada vez mais distante da prática e, conseqüentemente, afastando-se da práxis, o aprender será um processo estático de dar informações a um indivíduo que repete mecanicamente as instruções ou normas."

Entendemos como fundamental que as docentes superem a dicotomia teoria-prática, pela constante busca de uma compreensão dialética desses dois pólos, na realidade vivida. Caso contrário o processo ensino-aprendizagem será sempre um instrumento de manutenção das estruturas de dominação.

SANTI" questiona a formação do docente, considerando que deva ser suficientemente preparado tecnicamente, além de ser atualizado, crítico de seu contexto e de sua própria atuação, para que possa formar futuros profissionais, preparados para entender, agir e intervir na realidade de atuação.

Acreditamos que a lacuna existente na capacitação docente, relativa à área da prática de enfermagem, poderia ser amenizada pela integração docente assistencial, que vem sendo reconhecida, como de grande valia para a formação discente.

Nesta perspectiva, o conceito de integração docente assistencial, é concebido como "a união de esforços em um processo de crescente articulação entre instituições de educação e de serviço de saúde adequados às reais necessidades da população, a produção de conhecimentos e à formação de recursos humanos necessários." 10

CIAMPONE et $a^{14}$ entendem a integração docente assistencial como o estabelecimento de uma 
relação de trabalho entre uma instituição de ensino e uma instituição prestadora de serviços de saúde, de forma a possibilitar aos estudantes e professores da primeira, trabalhar em conjunto com o pessoal da segunda. Considerando ser essencial para que essa relação se efetive, o conhecimento das duas realidades: a assistencial e o ensino. Acreditam ainda que esse conhecimento da realidade seja essencial, para que ocorra delegação do poder, de autoridade e de responsabilidades, resultando em benefícios para as instituições envolvidas

Para NAGLE ${ }^{8}$ um dos grandes obstáculos da dicotomia entre a teoria e a prática é o preconceito existente que considera tudo de natureza técnica como necessariamente desprezível, impedindo que os docentes ampliem suas reflexões de natureza teórica em análises e discussões técnicas específicas, para que tenham uma efetiva aplicação prática.

Diante do exposto, consideramos que cabe aos docentes desmistificarem a prática da enfermagem pelo contínuo contato com a atuação do enfermeiro, desvelando, de forma crítica essa realidade, capacitando-se e, conseqüentemente promovendo a formação dos futuros profissionais.

\subsection{Percepção dos docentes quanto a capacitação teórico científica}

As falas dos docentes revelam que a carreira docente é uma prioridade da escola em questão, enfatizando assim o desenvolvimento acadêmico através dos cursos de Pós-Graduação. Foi considerado fator facilitador os cursos serem oferecidos na própria instituição de ensino e a possibilidade de realizarem cursos de Pós-Graduação em outras áreas.

Resgata-se, nos discursos, o fato da instituição de ensino não ter um programa formal de desenvolvimento contínuo dos docentes, com propostas de incentivos financeiros e oferecimento de bolsa de estudos, o que acaba, muitas vezes, por bloquear o crescimento teórico-científico dos docentes. Outro fator referido como dificultador desse desenvolvimento é a excessiva participação dos docentes $\mathrm{em}$ atividades administrativas.

E.1. "...nestas questões acadêmicas, propriamente ditas, nós temos a facilidade de ter o curso acontecendo aqui (...) eu não sou dispensada de outras atividades da escola (...) há uma exigência de uma série de outros compromissos administrativos que dificultam o desenvolvimento acadêmico.(...) Você acaba fazendo o Pós-Graduado mas não como você queria, porque você não tem todo o tempo para ler como você desejaria. (...) um outro fator que dificulta é a falta de incentivo financeiro (...) o Pós-Graduado foi válido e me fez crescer, possibilitando ampliar meus conhecimentos (...)."
Ao tratar-se de capacitação teórico-científica de docentes, considera-se, indicados os cursos de PósGraduação, por proporcionarem desenvolvimento para o ensino e para a pesquisa.

Cabe ressaltar que apesar dos cursos de PósGraduação visarem a capacitação qualificada de professores, algumas vezes, transformam-se em meros revisores da graduação, acrescidos da execução de um trabalho científico, nem sempre de qualificação aceitável. ${ }^{5}$

Para NAGLE ${ }^{8}$, o fato da pesquisa estar atrelada ao contrato de trabalho do docente, que exige a realização de investigação, a transforma numa atividade burocrática, conduzindo os docentes a "produzirem" pesquisas superficiais e de temas irrelevantes.

Segundo $\mathrm{PINTO}^{9}$, a capacitação contínua do educador para o cumprimento de sua tarefa social faz-se através de cursos de aperfeiçoamento, seminários, leituras de periódicos especializados, etc.e, fundamentalmente, pelo debate entre os docentes, pela crítica recíproca e pela permuta de pontos de vista sobre os problemas comuns da prática de ensino

NAGLE ${ }^{8}$ analisa que com a criação de especialidades surgiu a falsa impressão que um especialista pode esgotar, a discussão de um tema de sua disciplina, eliminando qualquer esforço de articulações entre temas da mesma área ou de áreas afins, considerando-se "proprietário" do tema. Deste fato resulta a fragmentação cada vez maior dos campos do conhecimento e a inexistência de um pensamento mais universalista.

Estes depoimentos mostram que as instituiçōes de ensino devem estar estruturadas de forma a promover, subsidiar e facilitar: a participação dos docentes em cursos de reciclagem, aperfeiçoamento e de pós graduação. Devem ainda promover o intercâmbio entre os docentes pela participação em congressos, reuniões científicas, palestras e encontros; o acesso à documentações científica nacional e estrangeira e aos acervos de bibliotecas; além de incentivarem a realização de pesquisas científicas que contribuam para o desenvolvimento da sociedade e do conhecimento humano. ${ }^{5}$

GUERRA $^{5}$ aponta ainda que o salário do docente é um fator de melhoria da qualidade na capacitação científica, alegando que deva ser compatível com sua sobrevivência, anseios de vida, aquisição de livros e separatas. Este fato justifica. se, principalmente por ser a universidade o local de formação de recursos humanos qualificados, bem como, a central de origem de pesquisas científicas. Dessa forma é simplista acreditar-se que o professor universitário esteja totalmente capacitado após 
concluir um curso de Pós-Graduação. Há necessidade de ampliarmos a visão à respeito de se considerar o desenvolvimento profissional docente como um processo contínuo, operacionalizado por cursos de reciclagem e aperfeiçoamento, bem como pelo intercâmbio com colegas e pelo acesso a um referencial teórico pertinente.

\subsection{Percepção dos docentes quanto a capacitação pedagógica}

As falas revelam que a instituição de ensino, onde atuam os sujeitos do estudo, não propicia a capacitação do docente no processo ensinoaprendizagem, ficando essa capacitação dependente do interesse do docente ou do grupo de trabalho.

Cabe ressaltar ainda que as entrevistadas consideraram que os recursos materiais e humanos da instituição são sub-utilizados, devido a inexistência de infra-estrutura capaz de orientar os docentes com relação às estratégias de ensino e à utilização de recursos audiovisuais.

E.1. "...ter feito a licenciatura abriu muito a minha cabeca em termos de educacão, e foi um curso que eu fiz nem pensando na graduaç̃o, foi pensando no meu trabalho de educação continuada no hospital, eu acho que esses cursos te ajuda."

E.2. “...em termos de estratégias, de processo ensinoaprendizagem, o pouco que eu tive foi na licenciatura, mas a licenciatura trabalhava muito mais com curso de auxiliar e técnico. (...) todos esses trabalhos de filosofia da educacão, processo educacional, eu não tive preparo nenhum, o que eu consegui era com leituras e discussões em grupo (...) O mestrado não deu essa bagagem enquanto docente, apesar de ser para ensino e pesquisa na parte de ensino não teve (...). um fator dificultador é você não ter apoio pedagógico, o apoio de como utilizar e elaborar os recursos audiovisuais. O professor perde muito tempo fazendo os recursos audiovisuais, sendo que se ele desse para outro profissional melhor preparado, teria uma qualidade melhor com menor custo. A parte de "slides" então, nem se fala, temos que pagar.(..) os recursos não estão bem organizados, se tivesse uma central, pelo menos, que você entrasse numa fila de espera, para a elaboração dos recursos (...) os nosso equipamentos são mal utilizados, sub-utilizados, nós temos vídeo, câmera, mas é muito pouco utilizado ainda, mesmo os micros, que são para o ensino e pesquisa, são mais utilizados para pesquisa e administrativo, porque nós não temos um suporte."

Acreditamos que a capacidade pedagógica do docente não se esgota na aplicação aprimorada de técnicas e métodos didáticos ou no planejamento do ensino. Compete ao professor conhecer-se profundamente como educador e pessoa e ter consciência crítica de sua conduta e desempenho, na busca de uma efetiva interação professor-aluno. Cabe ainda reconhecer o indivíduo-aluno globalmente, entendendo-o como um ser inserido em um contexto sócio-político-econômico-cultural.

A tônica da formação docente deve permear reflexões que levem à tomada de consciência da realidade e à desmistificação de crenças e valores que colocam o professor como absoluta fonte do saber, reguladora do conhecimento e da própria aprendizagem.

Para MENEZES ${ }^{6}$ a competência pedagógica não pode ser compreendida apenas como simples estratégias didáticas. O professor deve estar preparado para compreender o seu papel e do seu aluno, como de agentes de transformação da sociedade. Para tanto deve principalmente, compreender a situação global do aluno, para que os objetivos educacionais sejam estabelecidos adequadamente. Assim, o professor tem o desafio de superar a sua participação passiva no processo de ensino, como mero "repetidor" de aulas, refletindo, profundamente, sobre a dimensão do "porquê de ensinar", "o que ensinar" e "para quem ensinar".

MIZUKAMI $^{7}$ analisando a estruturação dos cursos de licenciatura, considera que deveriam possibilitar ao docente refletir sobre o próprio fazer pedagógico, suas implicações, pressupostos e determinantes, afim de conscientizá-lo de suas ações, para superá-las constantemente.

Reforça também a importância das reflexões e discussões em grupos de docentes, sobre a própria realidade e vivência de ensino, no intuito de clarificar as práticas pedagogicas.

ABREU: MASETTO ${ }^{1}$ consideram ainda que na capacitação do docente do ensino superior é comum existir uma lacuna, que se caracteriza pela falta do domínio da área educacional e pedagógica, tanto do ponto de vista amplo, mais filosófico, quanto do mais imediato, tecnológico.

Comparando as considerações desses autores com as falas clos docentes de enfermagem, onde pudemos depreender os anseios e conflitos docentes referentes à capacitação do professor, percebemos também uma lacuna no que diz respeito a área pedagógica.

Acreditamos ser essencial que sejam estimuladas reflexões à respeito da capacitação docente na área de enfermagem considerando-se os aspectos do conhecimento, da competência, da predisposição, das atitudes, dos valores, e os aspectos relativos ao ambiente específico, filosofia e estrutura organizacional do ensino, para que haja uma conscientização crítica da realidade educacional, e conseqüentemente, uma renovação da ação dos professores no processo ensino-aprendizagem. 
Cônscios desta realidade do ensino superior, reconhecemos que as universidades públicas, na maioria das vezes, valorizam primordialmente a pesquisa em detrimento do ensino, não oferecendo infra-estrutura e assessorias pedagógicas, nem mesmo incentivos e subsidios para o desenvolvimento e aperfeiçoamento dos docentes na aréa educacional.

\subsection{Considerações dos docentes quanto a identificação com o ensino.}

As docentes relatam uma predisposição, ou seja, uma tendência para a área de educação, ficando evidente o interesse pelo relacionamento e desenvolvimento de pessoas e também pela vida acadêmica.

E.1. "Eu gostava muito da área de humanas, eu sempre gostei muito de ler e escrever (...) sempre fui muito ligada a saúde pública, porque a educação, a relação com as pessoas sempre foi muito forte em mim (...) eu sempre me detinha muito na educação do paciente, em programas, na relação, no "papo", eu sempre gostei daquilo que a gente chamava na época do "tal de apoio psicológico" (...) mas tinha uma coisa super forte com a educação, com a coisa de ser professora, coma vida acadêmica, de estudar, ler. Sempre fui muito ligada a isso!

GUERRA $^{5}$ considera que a opção por uma profissão é, absolutamente, um ato voluntário e, para ser bem sucedida, deve ser fruto de uma vocação do indivíduo. Consideramos esta percepção simplista e ingênua, pelo fato de dissociar o homem do seu mundo, ocultando as múltiplas relações que ele estabelece com a sociedade na qual está inserido.

Portanto, partimos do pressuposto que o indivíduo é um ser social e os fatores determinantes de sua expectativas, projetos e ações, do modo de ver o mundo, os outros e ele mesmo, são definidos a partir das experiências de vida e das primeiras relações que o homem estabelece com o mundo.

Segundo CIAMPA ${ }^{3}$, na temática do âmbito profissional, freqüentemente, há a afirmação da profissão como uma vocação. Entretanto não é possível dissociar o estudo da identidade do indivíduo com o da própria sociedade na qual ele está inserido. As diversas possibilidades de configurações de identiclades profissionais estão relacionadas com as diferentes organizações sociais.

Nesse sentido consideramos que é no contexto histórico e social em que o homem vive e, que emergem as possibilidades ou impossibilidades, os modos $\mathbf{e}$ as alternativas de identidade profissional.

Assim, para o indivíluo assumir o desafio de educar e não apenas transmitir informações, mas de interagir com o outro indivíduo percebendo suas limitações, habilidades e capacidades globais, deve analisar a sua identidade profissional dentro de múltiplos cenários, onde devem ser enfocadas suas características individuais, sua história de vida e suas relações sociais.

\section{CONCLUSÕES}

O professor, considerado como elemento mediador do processo ensino-aprendizagem, tem influência direta nas situações que ocorrem em sala de aula, no relacionamento aluno/professor, no planejamento e adequação das condições de aprendizagem e no relacionamento com os demais docentes. Nessa perspectiva, percebemos a necessidade da capacitação profissional contínua do docente para o ensino em todas essas dimensões.

Com esse estudo pudemos resgatar a capacitação do professor como resultante de um processo complexo e contínuo de preparo técnico, teórico e pedagógico. Constatamos ainda que o problema da capacitação docente deve ser estudado dentro dos múltiplos cenários técnico, econômico, político, social, ético, histórico e psicologico.

Acreditamos que as reflexões dos docentes a respeito da realidade de ensino na sua totalidade favorecem a tomada de consciência e interferem, positivamente, na sua formação crítica. Consideramos, ainda, que há a necessidade das universidades criarem centros de formação e atualização de professores e estabelecerem políticas de recursos humanos compatíveis com as transformações sociais e com uma prática renovadora de ação educacional.

\section{REFERÊNCIAS BIBLIOGRÁFICAS}

1. ABREU, M.C. de; MASETTO. M.T. O professor universitário em aula. São Paulo, MG Editora Associados, 1987.

2. BARDIN, L. Análise de conteúdo. Lisboa, 1977.

3. CIAMPA, A.C. Identidade. In: LANE, S. ; CODO, W. (org) Psicologia social: o homem em desenvolvimento. São Paulo, Brasiliense, 1985. p. 58.75.

4. CIAMPONE, M. H. T. et al. Uma experiência de ensino na disciplina administraça aplicada à enfermagem Trabalho apresentado no IV ENFSUDESTE, Sao Paulo, 1991.

5. GUERRA, M. de O. Formação de recursos humanos para o desenvolvimentomcientífico na Universidade: estratégia para a capacitação científica. Rev. Adm. v. 21, n. 3, p. 43-7, 1986.

6. MENEZES, L. C. de. Formar professores: tarefa da universidade. In: CATANI, D. B. et al. Universidade escola e formaçao de professores. São Paulo, Brasiliense, 1987. p. $115-25$. 
7. MIZLKKAMI, M. G. Ensino: as abordagens do processo. São Paulo, EPU, 1986.

8. NAGLE, J. As unidades universitárias e suas licenciaturas: educadores X pesquisadores. In : CATANI, D. B. et al. Universidade, escola e formação de professores. São Paulo, Brasiliense, 1987. p. 171-72.

9. PINTO, A. V. Sete liçes sobre educaçao de adultos. Sao Paulo, Cortez, 1982.
10. ROCHA, I. M. B. ; SA, M. P. C. de. Diagnóstico avaliativo da prática da disciplina administração aplicada à enfermagem. Enf.Cient., v. 1, 11. 3, p. 16-9, 1991.

11. SANTI, M. C. de. Revelando a dimensao educadora do professor de enfermagem. São Paulo, 1984. 87p. Dissertação (mestrado) - PUC-SP.

12. SILVA, M. J. P. da et al. Educạ̧ao continuada: estratégia para o desenvolvimento do pessoal de enfermagem. São Paulo/ Rio de Janeiro, EDUSP, 1981.

1. História de vida (Relação com a enfermagem e com o ensino)

2. Como você percebe a sua capacitação profissional para o ensino?

3. Quais são os fatores bloqueadores e facilitadores para a sua capacitação? 